\title{
Impacts of Toothache on Daily Activities of Children Aged 5 to 9 Years in Kerman, Iran
}

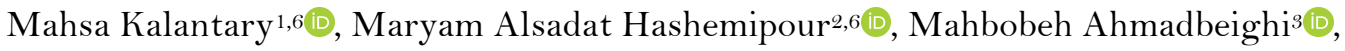 \\ Leila Shafie Bafti๋ ${ }^{+}$, Amir Reza Gandjalikhan Nassab ${ }^{5}$ (i)
}

${ }^{1}$ Department of Oral and Maxillofacial Pathology, Dental School, Kerman University of Medical Science, Kerman, Iran. 2Department of Oral Medicine, Dental School, Kerman University of Medical Science, Kerman, Iran.

${ }^{3}$ Department of Pediatric Dentistry, Dental School, Shahrekord University of Medical Science, Shahrekord, Iran.

${ }^{4}$ Department of Pediatric Dentistry, Dental School, Kerman University of Medical Science, Kerman, Iran.

${ }^{5}$ School of Medicine, Kerman University of Medical Science, Kerman, Iran.

${ }^{6}$ Kerman Social Determinants on Oral Health Research Center, Kerman University of Medical Sciences, Kerman, Iran.

Author to whom correspondence should be addressed: Maryam Alsadat Hashemipour, Department of Oral Medicine, Dental School, Kerman University of Medical Science, Kerman, Iran. Phone: +091 32996183. E-mail: m_s_hashemipour@yahoo.com.

Academic Editors: Alessandro Leite Cavalcanti and Wilton Wilney Nascimento Padilha

Received: 16 May 2019 / Accepted: 18 November 2019 / Published: 14 January 2020

How to cite this article: Kalantary M, Hashemipour MA, Ahmadbeighi M, Shafie L, Nassab ARG. Impacts of toothache on daily activities of children aged 5 to 9 years in Kerman, Iran. Pesqui Bras Odontopediatria Clín Integr. 2020; 20 :e4918. https://doi.org/10.1590/pboci.2020.027

\begin{abstract}
Objective: To investigate the impacts of toothache on the daily activities of children aged 5 to 9 years. Material and Methods: A cross-sectional analytical study was conducted among 465 children (220 boys and 245 girls) aged between 5-9 years, using the Child Dental Pain Questionnaire (Child-DPQ), in the city of Kerman. They were categorized into two groups based on the clinical status: (1) untreated dental caries and (2) no dental caries or treated dental caries. For data analysis, the Chi-square, Mann-Whitney test, multiple logistic regressions, Spearman's correlation coefficient and t-test were used. Results: Regarding the severity of pain, about $28.3 \%$ reported mild pain, $30.1 \%$ moderate pain, and $21.9 \%$ very severe pain. The prevalence of reported dental pain increased by increasing the number of reported dental visits and more strongly among those having $\mathrm{dmft}>1$. Toothache in children caused to stop eating (73.3\%) and to sleep (63.8.1\%) and provoked a dental visit in more than $40 \%$. Conclusion: The toothache stopped many children eating and sleeping and provoked a dental visit in more than $40 \%$. Among the children under study, $55.9 \%$ had to miss school.
\end{abstract}

Keywords: Child; Dental Caries; Toothache; Surveys and Questionnaires. 


\section{Introduction}

Oral health is an essential component of public health that has a great impact on the quality of life, especially concerning to chewing ability and the occurrence of pain and discomfort [1]. Many people through the world, especially the poorest segment of the international community, are still affected by several oral diseases despite the great advances in oral health care in recent decades [1]. One can mention to dental caries as an important disease [2]. There is an obvious and direct relationship between oral health and dental pain and also one can recall that dental pain is an important result of untreated dental caries. Studies have shown that assessing the impact of oral diseases on the quality of life may be useful in planning for oral health care service [3-9].

Pain is a subjective phenomenon, which should be measured by self-report [10]. In assessing oral health, any disruptions in normal physical, psychological and social functioning due to dental pain is important. Regarding oral health, adults and children have a different perception of the impact of a health problem on their life quality. It is due to this fact that children have a one-dimensional view toward physical and emotional development of themselves [11,12].

Dental pain may be produced by untreated dental caries, which in turn results in impacts of affected play and sleep, avoidance of certain types of food, and decreased school performance [6,13,14]. Dental pain is known to have both biological and psychosocial components based on the biopsychosocial model. Therefore, dental pain perceptions are complex functions of socio-demographic status, individual behaviors such as knowledge, beliefs, and expectations, besides the fundamental pathological cause of dental caries $[15,16]$.

The studies show that conditions such as erosion, trauma and exfoliation of primary teeth can also give rise to dental pain. Based on the study of the epidemiology of dental pain and dental caries in child populations, it was found that among children, dental pain is prevalent even in contemporary populations with historically low levels of caries experience [6]. The previous research works on the oral impacts of the mouth and teeth were done on adults and elderly populations. Recently, similar studies on the children in the various age group have been conducted in different parts of the world $[5,17,18]$. The present study aims to impacts toothache on the daily activities of children aged 5 to 9 years.

\section{Material and Methods}

\section{Study Design}

A cross-sectional analytical study was conducted among 465 children aged between 5 and 9 years in the Kerman city in Iran who referred to the Department of Pediatrics in the school of dentistry, dental clinics and pediatrician's offices from September 2013 to September 2015 because of toothache. In the time of the study, there were 220 dentists in Kerman. The aim of this study was explained for parents of these children, and in case of their consent, they were given the Child Dental Pain Questionnaire (Child-DPQ) [19].

\section{Data Collection}

Initially, a pilot study was performed to test the practicability of using the questionnaire on 7-year-old children. This investigation was done on a group of 30, 7 years old school children, those referred to the Department of Pediatric Dentistry at Kerman University, and the questionnaire was tested for validity or reliability. The validity of the questionnaire was evaluated by 10 specialists in Kerman, Iran. They were asked to express their opinions on each question by the words: totally appropriate, appropriate, no idea, inappropriate and totally inappropriate. After evaluation by the specialists, the level of the questions and their 
comprehensibility were evaluated. The validity of the questionnaire was good. The questionnaire was validated as a group one, with overall validity equal to $79 \%$, while the validity co-efficient for each question was between $77-89 \%$. The questionnaire's reliability was 0.8 , which is in the range of good ones.

\section{Questionnaire Survey}

The study was conducted using a structured questionnaire and a clinical examination. According to an assumed prevalence of reported dental pain, a sample size of 465 children was calculated. In order to investigate the effect of pain on patients' lifestyles, two different groups should be chosen. Besides, the distribution of children in these two groups was done after the examination. Such that at first, 246 children with toothache were dentally examined and then they were distributed into two groups: G 1 - untreated dental caries (true pain or case group) and G 2 - no dental caries or treated dental caries (false pain or control group). They were considered into two different groups because of investigating the effects of pain on their daily activities. The questionnaire, which is a structured one, includes various socio-demographic and oral health related variables. The questionnaires were prepared and written based on the children's language, which is in consistence with children's understanding. These questionnaires were randomly given out to children. They were physically able to answer the questionnaire and also had tooth pain. For the present investigation, exclusion criteria include general physical disability and pain or discomfort in other parts of the body (except the mouth). When completing the questionnaire, demographic information, including sex and age of child, job, and education level of parents were recorded [17-19].

In order to avoid missing cases to follow up, which occurs in the self-directed method, the questionnaire was applied in the form of an interview. In the meanwhile, participants were assured of the confidentiality of the responses and they are solely used for statistical analysis.

The Child-DPQ, a questionnaire developed previously [19] in 2011 that was standardized for Persian children was used [20]. This questionnaire has been designed based on 3 subscales, including (1) prevalence, (2) severity, and (3) impact of the dental pain on quality of life for children and consists of 6 questions (2 items in each subscale). For every person, the total score and the score for each subscale are calculated in the questionnaire, in which the total score can be o or ranges from 6-15. The better status for oral health was indicated by the lower score. The answer "No" to the first question by a child makes other questions not applicable (score $=0)$ [19]. If a child answers "Yes" to the first question, then answers to the next items are at least score 1. The Child-DPQ questionnaire has been standardized for Persian people.

Self-reported dental pain was assessed using one single question. It is asked from participants to answer this question that whether or not they had experienced dental pain during the previous four weeks, and the response categories were given as "Yes" (1) and "No" (0) [19]. According to the previous studies $[11,12,15,16]$, the most important factor of toothache in children is tooth decay, such that the factors as erosion, trauma and exfoliation of primary teeth are less important. It is worth mentioning that in the present study, all of these factors were omitted, and only the special cases with tooth decay were under investigation.

\section{Clinical Examination}

The clinical examination was carried out under field conditions in the dentistry unit by one dental student, whereas the observations were recorded by a trained assistant. All children were carried out by a dentistry student, such that she examined 30 children during two weeks under her supervisor. Using a set of equipments including a unit lamp as a source of illumination, mirror dentistry, and dental probes, students were examined whilst seated on a unit [17-19]. 
Cotton roles were used for cleaning and drying the teeth before being examined for caries using the decayed, missing and filled tooth index $(\mathrm{dmft})$ [21]. The presence of caries was recorded when a lesion in a pit/fissure or on a smooth surface had a detectable softened floor, undetermined enamel, softened wall or a temporary filling in addition to sticky enamel lesions [21]. The criteria for considering a tooth as a missing one was a history of extraction due to pain and or the presence of a cavity (a cavity is due to tooth decay that dentists cannot do any restoration or stainless steel crowns (SSC) and the only way is extraction).

Statistical Analysis

In the analysis, the children were categorized into two groups based on the clinical status: (1) untreated dental caries and (2) no dental caries or treated dental caries. The t-test was used to evaluate the impact of toothache on daily life and actions taken among children with a toothache and absent or treated caries. The Mann-Whitney nonparametric test was used to evaluate differences in the mean scores of both groups, dental pain regressed upon socio-demographic characteristics, subjective oral health ratings and dental status, unadjusted and adjusted was conducted using multiple logistic regression. Univariate analyses were performed by the use of the Chi-square statistics. A p-value of $<0.05$ was considered statistically significant, and the statistical analysis was performed using the SPSS 21 software (IBM Corp., Armonk, NY, USA).

\section{Ethical Considerations}

This study was approved by the Ethics Committee of Kerman University of Medical Sciences (No.K.93.62).

\section{Results}

In this study, 465 children aged between 5 and 9 years were evaluated, out of them 385 children (200 girls and 185 boy) had untreated dental caries (Table 1). The prevalence of reported dental pain increased by increasing the number of reported dental visits and more strongly among those having $\mathrm{dmft}>1$.

Table 1. Distribution of participants who reported dental pain by socio-demographics, behavioral and clinical characteristics.

\begin{tabular}{|c|c|c|c|}
\hline Variables & $\begin{array}{l}\text { Total } \\
\text { N (\%) }\end{array}$ & $\begin{array}{c}\text { Group } 1 \\
\mathrm{~N}(\%)\end{array}$ & $\begin{array}{c}\text { Group } 2 \\
\mathrm{~N}(\%)\end{array}$ \\
\hline \multicolumn{4}{|l|}{ Age (Years } \\
\hline $5-\leq 7$ & $226(48.6)$ & $171(44.4)$ & $55(68.7)$ \\
\hline$>7-9$ & $239(51.4)$ & $214(55.6)$ & $25(31.3)$ \\
\hline \multicolumn{4}{|l|}{ Gender } \\
\hline Girls & $245(52.7)$ & $200(51.9)$ & $45(56.2)$ \\
\hline Boys & $220(47.3)$ & $185(48.1)$ & $35(43.7)$ \\
\hline \multicolumn{4}{|l|}{ Dental Visits } \\
\hline Never & $15(3.2)$ & $7(1.8)$ & $8(10.0)$ \\
\hline Once & $87(18.7)$ & $45(11.6)$ & $42(15.0)$ \\
\hline Twice or More & $363(78.1)$ & $333(86.6)$ & $30(75.0)$ \\
\hline \multicolumn{4}{|l|}{ Dental Appearance } \\
\hline Satisfied & $300(64.5)$ & $230(59.7)$ & $70(87.5)$ \\
\hline Dissatisfied & $160(35.5)$ & $150(40.3)$ & $10(12.5)$ \\
\hline \multicolumn{4}{|l|}{ Oral Problems } \\
\hline None & $400(86.1)$ & $330(85.7)$ & $70(87.5)$ \\
\hline One & $40(8.6)$ & $30(7.7)$ & $10(12.5)$ \\
\hline Two & $25(4.3)$ & $25(6.6)$ & $\mathrm{o}(\mathrm{O} . \mathrm{O})$ \\
\hline
\end{tabular}


Regarding the severity of pain, about 28.3\% (132 children) reported mild pain, 30.1\% (140 children) moderate pain, and 21.9\% (102 children) very severe pain. The important triggers of dental pain were cold drinks or food and also biting and sweets (Table 2).

Table 2. Severity and provoking factors of toothache among children who reported toothache in the previous 4 weeks.

\begin{tabular}{lcc}
\hline Characteristics of the Toothache & $\begin{array}{c}\text { Group 1 } \\
\text { N }(\%)\end{array}$ & $\begin{array}{c}\text { Group 2 } \\
\text { N }(\%)\end{array}$ \\
\hline Pain Severity & $10(2.6)$ & $15(19.7)$ \\
No Pain & $83(21.5)$ & $49(59.3)$ \\
Mild Pain & $125(32.5)$ & $15(19.7)$ \\
Moderate Pain & $65(18.1)$ & $1(1.3)$ \\
Severe Pain & $102(26.5)$ & $0(0.0)$ \\
Very Severe Pain & & \\
Got Pain with & $280(77.8)$ & $65(81.2)$ \\
Sweets & $320(88.9)$ & $20(25.0)$ \\
Cold & $340(94.4)$ & $5(6.2)$ \\
Hot & $85(23.6)$ & $0(0.0)$ \\
Biting & $50(13.8)$ & $0(0.0)$ \\
Wobbly Tooth & & \\
\hline
\end{tabular}

The total score obtained in the questionnaire for Group 1 was $9.25 \pm 2.12$ (Table 3). There was a statistically significant difference between the mean score for the total scale, prevalence, severity, and impact of the dental pain among children with untreated dental caries (Group 1) and children with no dental caries or treated dental caries (Group 2) (Table 3).

Table 3. Discriminate validity: total and subscale scores for both groups.

\begin{tabular}{lccccc}
\hline \multicolumn{1}{c}{ Variables } & \multicolumn{2}{c}{ Group 1 } & \multicolumn{2}{c}{ Group 2 } & p-value $^{*}$ \\
& Mean (SD) & Median & Mean (SD) & Median & 0.001 \\
\hline Total Scale & $9.25 \pm 2.12$ & 9.5 & $1.15 \pm 1.22$ & 0.00 & 0.002 \\
Prevalence Subscale & $4.12 \pm 0.24$ & 4 & $0.41 \pm 0.09$ & 0.00 & 0.001 \\
Severity Subscale & $6.13 \pm 0.24$ & 6 & $0.65 \pm 0.14$ & 0.00 & 0.001 \\
Impact Subscale & $4.55 \pm 0.65$ & 5 & $0.35 \pm 0.12$ & 0.00 &
\end{tabular}

*Mann-Whitney U test.

Because of the pain, toothache stopped many children eating (58.3\%) and sleeping (65.8\%) and provoked a dental visit in more than $40 \%$. Besides, $55.9 \%$ had to miss school (Table 4 ).

Table 4. Impact of toothache on daily life and actions taken among children with toothache.

\begin{tabular}{|c|c|c|c|c|}
\hline Items & Answers & $\begin{array}{c}\text { Group } 1 \\
\mathrm{~N}(\%)\end{array}$ & $\begin{array}{c}\text { Group } 2 \\
\mathrm{~N}(\%) \\
\end{array}$ & p-value \\
\hline \multirow[t]{2}{*}{ Have you ever had a toothache? } & No & $10(2.6)$ & $15(18.7)$ & 0.01 \\
\hline & Yes & $375(97.4)$ & $65(81.3)$ & \\
\hline \multicolumn{5}{|l|}{ When was your last toothache? } \\
\hline & Not Applicable & $10(2.5)$ & $15(18.7)$ & 0.001 \\
\hline & More than a Month & $10(2.5)$ & $7(8.8)$ & \\
\hline & Last Month & $15(4.0)$ & $8(10.0)$ & \\
\hline & Today & $340(93.3)$ & $50(62.5)$ & \\
\hline \multicolumn{5}{|c|}{ Did you cry at the worst moment of a toothache? } \\
\hline & No & $10(2.5)$ & $30(37.5)$ & 0.003 \\
\hline & Yes & $350(97.5)$ & $50(62.5)$ & \\
\hline
\end{tabular}


How was it when the pain was at its worst? (Face scale)

$\begin{array}{lccc}\text { Mild Pain } & 58(15.4) & 50(62.5) & 0.001 \\ \text { Moderate Pain } & 146(38.9) & 25(31.2) & \\ \text { Severe Pain } & 69(18.4) & 5(6.3) \\ \text { Very Severe Pain } & 10(27.2) & 0(0.0)\end{array}$

Were you awakened at night by the pain?

$\begin{array}{lccc}\text { No } & 80(21.3) & 69(86.7) & 0.002 \\ \text { Yes } & 295(78.7) & 11(13.3) & \end{array}$

Were you unable to carry out any normal tasks because of toothache?

$\begin{array}{lccc}\text { No } & 110(29.3) & 74(93.3) & 0.001 \\ \text { Yes } & 265(70.7) & 6(6.7) & \end{array}$

Were you unable to going to your school because of toothache?

\begin{tabular}{llll} 
No & $135(36.0)$ & $60(75.0)$ & 0.001 \\
Yes & $240(64.0)$ & $20(25.0)$ & \\
\hline
\end{tabular}

*T-test.

The present study showed that there is a statistically significant relationship between the odds ratio of tooth pain and education level of parents, i.e., those children with low educated parents experience more tooth pain.

Socio-demographics entered in the first step explained $1.9 \%$ of the variance in reported dental pain. In other words, dental pain is dependent on socio-demographics and self-reported oral health. Also, dental pain was associated with reporting at least two oral problems (dental appearance and having visited a dentist twice during the previous 3 years) (Table 5).

Table 5 Dental pain regressed upon socio-demographic characteristics, subjective oral health ratings and dental status.

\begin{tabular}{|c|c|c|c|c|}
\hline Variables & OR Crude & $95 \% \mathrm{CI}$ & OR Adjusted & $95 \% \mathrm{CI}$ \\
\hline \multicolumn{5}{|l|}{ Age Group } \\
\hline $5-\leq 7$ & 1 & $1.55-7.8$ & 1 & $0.49-2.1$ \\
\hline$>7-\leq 9$ & 3.2 & & 0.99 & \\
\hline \multicolumn{5}{|l|}{ Gender } \\
\hline Boys & 1 & $1.01-3.19$ & 1 & $1.09-3.01$ \\
\hline Girls & 1.8 & & 0.81 & \\
\hline \multicolumn{5}{|l|}{ Oral Problems } \\
\hline None & 1 & & 1 & \\
\hline One & 1.5 & $1.2-2.4$ & 1.3 & $1.3-2.4$ \\
\hline Two & 2.1 & $1.9-3.9$ & 1.9 & $1.7-3.7$ \\
\hline \multicolumn{5}{|l|}{ Dental Visits } \\
\hline Never & 1 & & 1 & \\
\hline Once & 2.2 & $1.2-2.9$ & 2.1 & $0.7-2.5$ \\
\hline Twice or More & 2.5 & $1.5-3.8$ & 2.3 & $1.3-3.0$ \\
\hline \multicolumn{5}{|l|}{ Dental Appearance } \\
\hline Satisfied & 1 & $1.7-4.4$ & 1 & $1.4-4.1$ \\
\hline Dissatisfied & 2.9 & & 2.6 & \\
\hline \multicolumn{5}{|l|}{ Dental Caries } \\
\hline $\mathrm{DMFT}=1$ & 1 & & 1 & \\
\hline $1<\mathrm{DMFT}<3$ & 1.5 & $1.2-2.6$ & 1.3 & $1.1-2.4$ \\
\hline $\mathrm{DMFT} \geq 3$ & 1.6 & $1.1-2.9$ & 1.4 & $1.1-2.5$ \\
\hline
\end{tabular}

\section{Discussion}

Pain is a complex, multidimensional phenomenon, which is caused by physical and chemical processes in the central and peripheral nervous system [13]. In many countries, dental pain, such as tooth decay, is a 
common disease that has a great effect on the quality of life and should be measured by specific instruments $[13,17,18]$. The prevalence of this disease ranges from $5 \%$ to $88 \%$, such that the wide prevalence range is due to the definition of the pain, measurement method, and many other factors [13,22,23].

According to the findings in the present work, the prevalence of dental pain was high (94.6\%) among $5-9-y r-o l d$ children. The value of toothache ranged from $48 \%$ to $88 \%$ in a similar age group according to the previous studies $[13,18,24]$. Also, the toothache range was reported $13 \%$ to $24 \%$ in the study on Sri Lanka children [5], while other authors reported a prevalence of $70 \%$ [18]. The difference between the results obtained in those studies is due to variations in patterns and severity (particularly the dental caries levels), culture and even pay attention to children.

Based on previous studies in Brazilian adolescent populations, the prevalence of toothache was $32 \%$ [4] and 62\% in Uganda [25]. In child populations, $70 \%$ prevalence of dental pain was reported in South African [18] and 73\% of New Zealand [26] children with good oral status had at least one dental symptom in the past year. The difference between the results obtained in those studies is due to the instrument of study, culture, and age population in studies.

Self-reported dental pain is subject to misclassification because children fail to identify the pain as dental in origin and might include other conditions in their reports [6]. The prevalence estimated in this study accords with the lifetime prevalence (any toothache ever) reported among 5-15-year-old Australian school children and that of 8-year-olds from the city of Harrow in England [13,27]. It was in accordance with pain experienced during the last four weeks among 8-year-olds from Sri Lanka [5] and other studies [28,29]. However, in the present study, it was found that the prevalence of dental pain is higher than that reported in Brazilian school children [17,30].

The present study showed that the score obtained in the questionnaire was different between two groups of children with and without dental caries and also mean scores of total scale and subscales in children with untreated dental caries were higher than those without dental caries or with treated dental caries. These findings are similar to those previously reported [12,19].

Other studies have shown that the average number of decayed, missing or filled teeth is higher among children whom tooth pain keeps them awake at night or causes child sleep disorder [31]; and children with dental caries experience more tooth pain than those without dental caries [32].

Comparison between the results of present work with a study conducted on children aged between 2 and 6 years in Ohio, USA (early childhood caries-related pain) [33], and also with similar works done in different part of the world is not possible, because the lack of standard instruments used and also due to different analysis and difference in population [33,34].

The reliability of dental self-reports items among children in New Zealand was previously investigated [30]. In that work, the sample in terms of age and method was similar to the present analysis, while only one item in the questionnaire was about dental pain.

This study showed that there is a direct relationship between the number of dental visits and dental caries and dental pain experience; these findings are similar to that of other studies [5,6,19,28,35-37]. Obviously, children's dental pain could be avoided and quality of family life improved through the strengthening of the preventive and therapeutic dental services for primary school children [37]. The association was moderately strong. However, from all children with different pain experiences, about $82.2 \%$ had untreated dental caries. Based on these studies, it is found that there is a strong clinical relationship between dental caries experience and dental pain among children $[5,19,36]$. It is worth mentioning that dental 
pain at these ages may be due to dental trauma, tooth eruption, and deciduous tooth loss [17-19]. It is clear that by strengthening preventive and therapeutic dental caries, dental pain can be prevented for school-aged children [38]. It is found in the present study that by controlling confounding factors (Logistic Regression Analysis - Odd Ratio), there is a relationship between the low parental educational level and increased dental pain among children. This founding is similar to the results obtained by other investigators [6,22,27$29,35,39]$

However, it was demonstrated that children in higher social classes are more seriously influenced by dental pain [40]. Evidence suggests that low family income and educational levels associated with increased dental pain in children [22]. The socioeconomic status of children took pale as a significant modifier of the association between caries experience and reported dental pain with the strongest relationship found in children from higher socioeconomic status families [17-19].

Previous studies of sub-Saharan African origin have identified a social gradient in dental caries experience with children from upper social classes being those most seriously affected [1]. An opposite result was revealed by contemporary evidence from industrialized countries, in which it was reported that the lower the material standard of living, the worse the oral health, whatever measure are used to assess this, be they clinical or self-reported indicators [16]. In addition, those children who have visited a dentist once or twice during the last year reported more dental pain than those who have not visited a dentist; these results are also similar to those of other studies $[28,29,39,40]$.

In the present study, about $86.1 \%$ of children had cried when experiencing dental pain; this figure is much higher than the rate of $18 \%$ reported previously [13]. There are several factors that can be the reasons for making this difference. They are the variance in the prevalence of dental caries and dmft in various countries, cultural emotional differences in dealing with children's reactions as well as the child's own feelings [17-19].

The incidence of dental pain prevented $55.9 \%$ of children to go to school and has influenced about $58.3 \%$ of children's play and sleep $(65.8 \%)$, which is in accord with previous studies [5,28,29]. These percentages are much higher than those reported by other authors (23\% and 33\%, respectively) [13]. The previous study revealed that the most common impact is difficulty in eating (71.4\%). Also, it was reported that $34 \%$ of children had oral pain, which did not allow them to sleep in the night [29]. The difference, in this case, can be due to the lower age of children considered in the present research work compared to the mentioned study as well as the difference in dental caries type and pain severity.

The pain degree found in this study was severed (14.1\%). This result is in contemporaneous with other investigations $[5,18,28,29]$. The most common factor to trigger oral pain in children was 'biting', which is in agreement with earlier studies [5,10].

Pain is necessarily a subjective phenomenon. Hence, self-reported pain is considered as a gold standard for assessing children's perceptual and mental experiences of pain [32]. To attain the desired result in any questionnaire, questions and items of the questionnaire should be concise, clear, easy to interpret and can easily be generalized to daily affairs. Besides, good questionnaires have acceptable validity and reliability and do not need complex training in order to use [19,31]. It should be mentioned that the present questionnaire has these characteristics and good validity and reliability in terms of Persian language among speaking children [20] and also has higher validity and reliability compared with two ones including children's health and life quality. 
Considering information obtained from the studied children, it is obvious that dental pain among children is an important problem with significant consequences for children, their parents, and society. The mentioned questionnaire can be used in future studies on pediatric dental caries and pain or the investigation of the results of treatment. Furthermore, it seems that further epidemiological studies about the effect of dental pain on family daily activities, social, physical, psychological performances among various age groups of children in studies with bigger sample size are needed so that dental pain can be considered as one of the influencing factors on children's quality of life.

\section{Conclusion}

It is found that the occurrence and impact of toothache in 5-9-years-old children is high in Kerman. The toothache stopped many children eating and sleeping and provoked a dental visit in more than $40 \%$. Among the children under study, 55.9\% had to miss school. In addition, future research works are needed to assess how effectively and efficiently dental services are responding to people suffering from dental pain.

\section{Authors' Contributions}

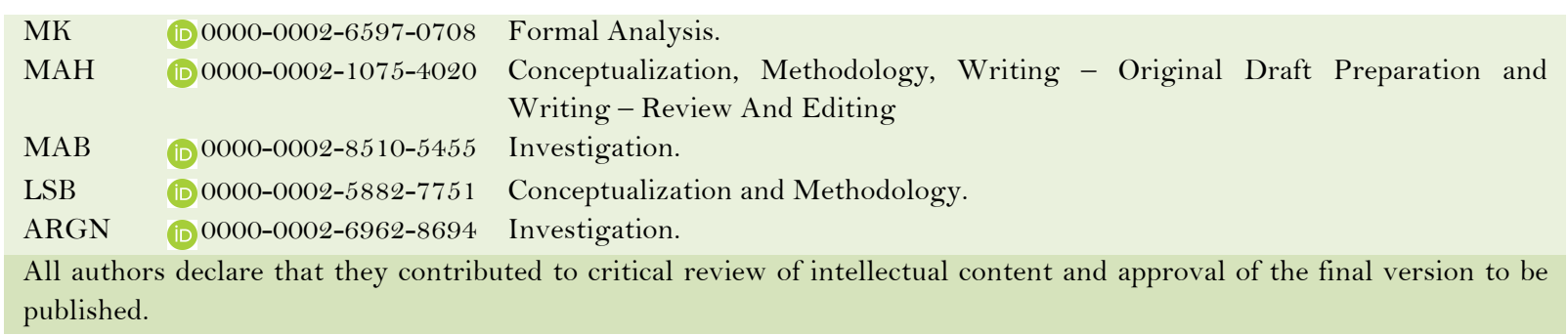

\section{Financial Support}

Kerman University of Medical Sciences (Grant No. K.93.62).

\section{Conflict of Interest}

The authors declare no conflicts of interest.

\section{Acknowledgement}

The authors would like to thank the Research Deputy for their financial support. Also, the authors would like to express their gratitude to the Vice Deputy of Research at Kerman University of Medical Sciences, for their financial support.

\section{References}

[1] Petersen PE. The World Oral Health Report 2003: continuous improvement of oral health in the 21 st century - the approach of the WHO Global Oral Health Programmed. Community Dent Oral Epidemiol 2003; 31(Suppl 1):3-23. https://doi.org/10.1046/j..2003.com122.x

[2] McGrath C, Bedi R. A national study of the importance of oral health to life quality to inform scales of oral health related quality of life. Qual Life Res 2004; 13(4):813-8. https://doi.org/10.1023/B:QURE.000002 1696.05528.4c

[3] Brazilian Ministry of Health. National Coordination of Oral Health. Oral Health Conditions of the Brazilian Population. SB Brazil 2003 Project. Main Results. Available at: http://portal.saude.gov.br/saude/arquivos/relatorio_ brasil_sorridente.pdf 2006. [Accessed on April 14, 2019].

[4] Goes PS, Watt RG, Hardy R, Sheiham A. Impacts of dental pain on daily activities of adolescents aged 14 to 15 years and their families. Acta Odontol Scand 2008; 66(1):7-12. https://doi.org/10.1080/00016350701810633

[5] Ratnayake N, Ekanayake L. Prevalence and impact of oral pain in 8-year-old children in Sri Lanka. Int J Paediatr Dent 2005; 15(2):105-12. https://doi.org/10.1111/j.1365-263X.2005.00602.x 
[6] Slade GD. Epidemiology of dental pain and dental caries among children and adolescents. Community Dent Health 2001; 18(4):219-27.

[7] Tickle M, Blinkhorn AS, Milsom KM. The occurrence of dental pain and extractions over a 3-year period in a cohort of children aged 3 to 6 years. J Public Health Dent 2008; 68(2):63-9.

https://doi.org/10.1111/j.1752-7325.2007.00048.x

[8] Tesch FC, Oliveira BH, Leão A. Measuring the impact of oral health problems on children's quality of life: conceptual and methodological issues. Cad Saude Pública 2007; 23(11):2555-64. https://doi.org/10.1590/s0102-311 x2007001100003

[9] Jokovic A, Locker D, Stephens M, Kenny D, Tompson B, Guyatt G. Validity and reliability of a questionnaire for measuring child oral-health-related quality of life. J Dent Res 2002; 81(7):459-63. https://doi.org/10.1177/154405910208100705

[10] Stinson JN, Kavanagh T, Yamada J, Gill N, Stevens B. Systematic review of the psychometric properties, interpretability, and feasibility of self-report pain intensity measures for use in clinical trials in children and adolescents. Pain 2006; 125(1-2):143-57. https://doi.org/10.1016/j.pain.2006.05.006

[11] Sevenhuysen GP, Trumble-Waddell J. A new perspective on quality of life. J Clin Epidemiol 1997; 50(3):231-42. https://doi.org/10.1016/s0895-4356(96)00376-9

[12] Barrêtto EP, Ferreira e Ferreira E, Pordeus IA. Evaluation of toothache severity in children using a visual analogue scale of faces. Pediatr Dent 2004; 26(6):485-91.

[13] Shepherd MA, Nadanovsky P, Sheiham A. The prevalence and impact of dental pain in 8-year-old school children in Harrow, England. Br Dent J 1999; 187(1):38-41. https://doi.org/10.1038/sj.bdj.4800197

[14] Levine RS, Pitts NB, Nugent ZJ. The fate of 1,587 unrestored carious deciduous teeth: a retrospective general dental practice based study from northern England. Br Dent J 2002; 193(2):99-103. https://doi.org/10.1038/sj.bdj.4801495

[15] Locker D, Miller Y. Subjectively reported oral health status in an adult population. Community Dent Oral Epidemiol 1994; 22(6):425-30. https://doi.org/10.1111/j.1600-0528.1994.tbo0791.x

[16] Lwanga SK, Lemeshow S. Sample Size Determination in Health Studies. Geneva: World Health Organization, 1991.

[17] Gherunpong S, Tsakos G, Sheiham A. The prevalence and severity of oral impacts on daily performances in Thai primary school children. Health Qual Life Outcomes 2004; 2:57. https://doi.org/10.1186/1477-7525-2-57

[18] Naidoo S, Chitke UME, Sheiman A. Prevalence and impact of dental pain in 8-10-year-olds in the western Cape. South Afr Dent J 2001; 56(11):521-3.

[19] Barrêtto ER, Paiva SM, Pordeus IA, Ferreira e Ferreira E. Validation of a child dental pain questionnaire instrument for the self-reporting of toothache in children. Pediatr Dent 2011 ; 33(3):228-32.

[20] Hashemipour MS, Ahmad Beighi M, Shafie L. Standardization of a child dental pain questionnaire in Persian children. [Thesis No:845]. Kerman University of Medical Science: Dental School, Kerman, Iran, 2013.

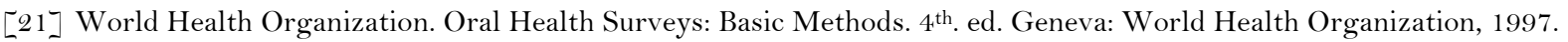

[22] Honkala E, Honkala S, Rimpela A, Rimpela M. The trend and risk factors of perceived toothache among Finnish adolescents from 1977 to 1997. J Dent Res 2001; 80(9):1823-7. https://doi.org/10.1177/00220345010800091001

[23] Gift HC, Atchinson KA, Dayton CM. Conceptualizing oral health and oral health related quality of life. Soc Sci Med 1997; 44(5):601-8. https://doi.org/10.1016/s0277-9536(96)00211-0

[24] Todd JE. Children's dental health in England and Wales, 1973. A survey carried out by Social Survey Division of the Office of Population Censuses and Surveys in collaboration with the Department of Dental Health, University of Birmingham for the Department of Health and Social Security. London: HMSO, 1975. 387p.

[25] Cortes MI, Marcenes W, Sheiham A. Impact of traumatic injuries to the permanent teeth on the oral health-related quality of life in 12-14-year-old children. Com Dent Oral Epidemiol 2002, 30(3):193-8. https://doi.org/10.1034/j.1600-0528.2002.300305.x

[26] Chen MS, Hunter P. Oral health and quality of life in New Zealand: a social perspective. Soc Sci Med 1996; 43(8):1213-22. https://doi.org/10.1016/0277-9536(95)00407-6

[27] Slade GD, Spencer AJ, Davies MJ, Burrow D. Intra-oral distribution and impact of caries experience among South Australian school children. Aust Dent J 1996; 41(5):343-50. https://doi.org/10.1111/j.1834-7819.1996.tbo3144.x

[28] Kiwanuka SN, Åstrøm AN. Self-reported dental pain and associated factors in Ugandan schoolchildren. Norsk Epidemiologi 2005; 15(2):175-82. https://doi.org/10.5324/nje.v15i2.216

[29] Mittal M, Dwivedi S, Vashisth P, Jaiswal D. Prevalence and impact of oral pain in 8 year-old children in India. J Dent Sci Oral Rehab 2012; 2:37-40.

[30] Nalweyiso N, Busingye J, Whitworth J, Robinson PG. Dental treatment needs of children in a rural sub-county of Uganda. Int J Paediatr Dent 2004; 14(1):27-33. https://doi.org/10.1111/j.1365-263x.2004.00514.x

[31] Jamieson LM, Thomson WM, McGee R. An assessment of the validity and reliability of dental self-report items used in a national child nutrition survey. Community Dent Oral Epidemiol 2004; 32(1):49-54. https://doi.org/10.1111/j.1600-0528.2004.00126.x

[32] Versloot J, Veerkamp JS, Hoogstraten J. Dental discomfort questionnaire: assessment of dental discomfort and/or pain in very young children. Community Dent Oral Epidemiol 2006; 34(1):47-52.

https://doi.org/10.1111/j.1600-0528.2006.00253.x 
[33] Easton JA, Landgraf JM, Casamassimo PS, Wilson S, Ganzberg S. Evaluation of a generic quality of life instrument for early childhood caries-related pain. Community Dent Oral Epidemiol 2008; 36(5):434-40. https://doi.org/10.1111/j.1600-0528.2007.00417.x

[34] Pau A, Croucher R, Marcenes W, Leung T. Development and validation of a dental pain-screening questionnaire. Pain 2005; 119(1-3):75-81. https://doi.org/10.1016/j.pain.2005.09.016

[35] Slade GD. The Oral Health Impact Profile. In: Slade GD. Measuring Oral Health and Quality of Life. Chapel Hill: University of North Carolina, 1997. pp. 93-104.

[36] Nomura LH, Bastos JLD, Peres MA. Dental pain prevalence and association with dental caries and socioeconomic status in schoolchildren, Southern Brazil, 2002. Braz Oral Res 2004; 18(2):134-40. https://doi.org/10.1590/S1806-83242004000200008

[37] Locker D, Jokovic A, Stephens M, Kenny D, Tompson B, Guyatt G. Family impact of child oral and orofacial conditions. Community Dent Oral Epidemiol 2002; 30:438-48.

[38] Bafti LS, Hashemipour MA, Poureslami H, Hoseinian Z. Relationship between body mass index and tooth decay in a population of 3-6-year-old children in Iran. Int J Dent 2015; 2015:126530. https://doi.org/10.1155/2015/126530

[39] Okullo I, Åstrøm AN, Haugejorden O. Social inequalities in oral health and in use of oral health care services among adolescents in Uganda. Int J Paediatr Dent 2004; 14(5):326-35. https://doi.org/10.1111/j.1365-263X.2004.00568.x

[40] Vigild M, Petersen PE, Hadi R. Oral health behavior of 12-year-old children in Kuwait. Int J Paediatr Dent 1999; 9(1):23-9. https://doi.org/10.1046/j.1365-263x.1999.00097.x 